\title{
People-centeredness in health system reform. Public perceptions of private and public hospitals in South Africa
}

\author{
Lebogang Maseko, BSc (OT), MPH (Health Systems and Policy), University of the Witwatersrand \\ Lecturer, Occupational Therapy Department, School of Therapeutic Sciences, Faculty of Health Sciences, University of the \\ Witwatersrand, Johannesburg, South Africa
}

\section{Bronwyn Harris, MA (Psychology), PhD (Public Health), University of the Witwatersrand}

Researcher, Centre for Health Policy/MRC Health Policy Research Group, School of Public Health, Faculty of Health Sciences, University of the Witwatersrand, Johannesburg, South Africa

Introduction: South Africa's planned National Health Insurance system seeks to transform and integrate public and private healthcare services, as part of wider efforts to realise universal health coverage. Ensuring quality, acceptable care is crucial for public buy-in to these changes. In this study the public perceptions of the country's private and state hospitals are explored. A better understanding may guide improvements in public sector services, and strengthen confidence and trust in health system reforms.

Methods: Eight qualitative focus group discussions were held with 54 participants delineated by race ('black' and 'white' South Africans) and experience (recent or indirect) of public and private hospital services. The views on quality of care, cleanliness, satisfaction, staff attitudes, origins of perceptions, and suggestions for improving state hospitals were explored.

Findings/results: Thematic content analysis revealed an almost-automatic initial perception that private hospitals are "good" and state hospitals "bad". However, on further exploration, a more nuanced understanding surfaced around the costs and affordability of private and public hospitals, and trust in and acceptability of health services.

Conclusion: Health systems are also human systems, with personal encounters at their heart. In order to acceptably serve people and society, policy emphasis is needed to build a culture of person-centred care in the public sector.

Key words: National Health Insurance, people-centeredness, health system reform, universal health coverage, public perceptions

\section{INTRODUCTION}

"We are working to reduce the exorbitant cost of private healthcare and make sure the public healthcare system is of good quality" (South African Minister of Health, Dr Aaron Motsoaledi, August, 20I5) $)^{1: 1}$.

Globally, many countries, including South Africa, are striving for universal health coverage (UHC). In an ongoing effort to address persistent injustice and access barriers, South Africa is implementing a National Health Insurance system (NHI) in which affordable, quality health care will be available for those who need it, regardless of 'who' they are, 'where' they live or their ability to pay'. The country's NHI White Paper (20I7) seeks to promote greater equity between people living in rural and urban areas and between people served by the public and private sectors ${ }^{3}$. The 'two-tier' privatepublic split in healthcare is highly inequitable, with the private sector serving just $16 \%$ of the population while absorbing almost half of the country's healthcare expenditure ${ }^{3}$. Broadly, $\mathrm{NHI}$ is directed towards integrating and improving access to services, providing quality care and installing a wider set of social protection measures aimed at improving equity in health access and outcomes ${ }^{4-6}$. As an integral part of healthcare, Occupational Therapy services are offered across all levels and sectors of the health system and as such any health sector reform will have an influence on these services.

On the financing side, the policy envisages that a single purchaser will integrate the private and public sectors and that a unified central fund will reduce the fragmentation and inequities inherent in the system ${ }^{7-9}$. The policy emphasises the need to reduce costs in the private sector, and also, to tackle perceived and real problems with quality of care $(\mathrm{QoC})$ in the public sector. $\mathrm{NHI}$ reforms are currently being piloted at a district level and efforts are underway to tackle QoC with primary health care re-engineering (20I I), the National Core Standards for Health Establishments (20I I), and the introduction of an Office of Health Standards Compliance (20I2), which aim to provide a benchmark for QoC across South Africa $^{7-9}$. Furthermore, facility-based and district-wide reforms such as the Ideal Clinic, Integrated Chronic Disease Management, Ward-Based Outreach Teams, and the contracting of privately-based general practitioners into state clinics are intended to improve the accessibility of services, while looking at innovative ways to draw together actors working in private and public care, including occupational therapists.

Ensuring good QoC at all levels is not only important for the $\mathrm{NHI}$ but should be a goal of any well-functioning health system $\mathrm{m}^{4,5,8,10}$. Alongside efforts to strengthen primary health care , there is also an emphasis on improving hospital services ${ }^{3}$. Public hospitals provide what is for most citizens the only available hospital care given the high costs of private hospitals ${ }^{11,12}$. In South Africa, occupational therapy and other rehabilitation services are delivered through both the public and private sectors. The NHI White Paper ${ }^{3}$ incorporates rehabilitation services as part of broader health system reform. However what and how these services will be provided is largely tacit and in need of further public engagement and consultation with professional bodies ${ }^{13}$. For occupational therapy, there is a policy imperative to gauge public perceptions of the health system. In order to support policy efforts to build an integrated, unified health system, it is important to understand how people perceive both public and private hospitals. Ultimately it is members of the public who, as beneficiaries and contributors to the healthcare system, will be affected by the $\mathrm{NHI}$ and will affect its implementation. The extent to which the $\mathrm{NHI}$ will be acceptable to society is critical 
to its success because people must feel confident about using the public sector ${ }^{11,14}$. Confidence can be demonstrated by, among other things, public willingness to access public healthcare facilities as their provider of choice. Choice of health service providers is influenced not only by cost and affordability, but also by perceptions and experiences of the public and private sector health care available ${ }^{15,16}$.

This paper focuses on public perceptions of state and private hospitals in South Africa and people's willingness to utilise available health services, which include occupational therapy services. We highlight issues surrounding the acceptability of health services, including trust and confidence in the health system and how these issues may be addressed to ensure buy-in from the public for the $\mathrm{NHI}$ system.

\section{LITERATURE REVIEW}

\section{Why does South Africa need NHI? The persistence of inequity}

Built in the interests of white capital, the apartheid health system reproduced massive racial and spatial inequalities in the availability of care and population health outcomes. In the early 1970s, for example, one doctor served 15,000 people living in the (black African) Bantustans compared to I,700 in the rest of the country, and tuberculosis rates and deaths were much higher in black and so-called coloured populations than amongst whites ${ }^{17,18}$. Utilisation of the then-expanding private health sector was also racially-skewed towards white users, and human and financial resources were increasingly drawn into private care. By $1980,40 \%$ of doctors worked in the private sector, increasing to over $60 \%$ by $1990^{12,18}$.

Since the country's first democratic elections in 1994, access to health care has remained inequitable, despite a number of progressive policies aimed at redressing past inequities ${ }^{19}$. The privatepublic split (and vast discrepancies in resources consumed by each sector) continues to reinforce unfair, avoidable discrepancies in access to services and health outcomes, thereby undermining efforts to achieve $\mathrm{UHC}^{19}$. Private hospital utilisation is largely limited to the relatively wealthy and employed who have private health insurance (often paid for as part of formal employment conditions of service) $)^{12,20}$.

Human resources are similarly mal-distributed between the private and public sectors. Private hospitals are generally better equipped in terms of resources, staffing and infrastructure ${ }^{\mid 2,21}$; attracting an estimated $79 \%$ of all doctors, with one specialist doctor serving fewer than 500 people on average (compared to nearly 11,000 people in the public sector $)^{11,12}$. There has also been a substantial decrease in the nurse-to-population ratio in the public sector, falling from I 49 to I I 0 professional nurses per I 00,000 between $1998^{22}$ and $2007^{18}$. In 2010 there were an estimated 81,925 public sector vacancies for all categories of nurses ${ }^{23}$. The national Forum for occupational therapy in the public sector (20I7) reports that in the rural provinces of Limpopo and Eastern Cape, there are 263 professionals (across all categories of occupational therapy) per 5.79 million people and 268 per 6.99 million respectively ${ }^{24}$.

The ratio between patients and health workers does not only reflect human resource shortages, but may have a negative impact on health worker attitudes, leading to reduced quality of care and demotivation among health workers in the public sector ${ }^{12}$. Public sector health workers in South Arica are frequently described as 'cruel' or 'uncaring' with little regard for patient confidentiality ${ }^{25-27}$. This has fuelled perceptions that the public health system is strained, under-resourced and has 'worsened' over time ${ }^{28}$. The optimal performance of the health system is thus dependent on addressing acceptability of care, alongside integrating the highly fragmented public-private split and overcoming human resource challenges ${ }^{9,23,29}$.

\section{Acceptability and why perceptions matter}

Acceptability of care cannot be understood outside of context ${ }^{25,} 30$. Context refers not only to the physical setting in which a behaviour, attitude or process takes place, but also the historical, socio- political, organisational and individual characteristics that influence $i^{31}$. Acceptability is mediated by contextually-bound meanings and perceptions of care, as well as experiences of services ${ }^{25,30}$. In South Africa, race and socio-economic status influence perceptions and expectations of care, as well as actual care provided ${ }^{32}$. Although race is no longer rated as the top source of division by South Africans, race and class remain intimately connected as determinants of material and social exclusion ${ }^{20}$. There is a social justice imperative for $\mathrm{NHI}$ to make care acceptable, alongside improving the health financing system and quality of care provided.

QoC manifests clinically, and also as service quality, responsiveness, patient satisfaction, trust, staffing, and cleanliness of facilities; all of which constitute the acceptability of health care services $^{10,17,33-35}$. If a health system cannot be trusted to guarantee a threshold level of quality, it may remain underutilised ${ }^{25}$. In Nepal in the 1990s, despite substantial state investment, utilisation of facilities remained low because of negative perceptions of quality ${ }^{4,36}$. Evidence suggests that people actively 'seek out' quality care, while (where possible) avoiding care perceived to compromise or undermine their health ${ }^{36}$. Studies in low-andmiddle-income-countries reveal that while increasing access and reducing costs are important, perceived quality may have a relatively greater influence on service user satisfaction ${ }^{37,38}$. Andaleeb ${ }^{37}$ found that regardless of clinical indicators, private hospitals in Bangladesh were perceived to offer better quality of care than public hospitals because of the high concentration of resources in the former. In a study of public views on health care in Sub-Saharan Africa, overall public satisfaction was found to be affected by accessibility of services, 'user-friendliness', the position of the user in the social structure, service experiences, encounters with providers, and corruption or dishonesty of service workers ${ }^{39}$. Perceptions of whether patients are treated respectfully and with dignity also matter ${ }^{17}$. In South Africa, it is a common perception that patients at public hospitals are rarely treated with respect and dignity, with attitudes of health workers being regarded as 'bad service' $\mid 1,40,41$. A better understanding of perceptions may guide $\mathrm{NHI}$ efforts to improve public sector services, and strengthen confidence and trust in health system reforms. In this study, we explore how members of the South African public perceive private and public hospitals, as well as their preferences for health care providers.

\section{METHODOLOGY}

\section{Study design}

In order to explore perceptions of private and public hospitals, an exploratory qualitative approach was followed. Qualitative methods are particularly suitable for exploring the 'hows' and 'whys' (reasons for) as well as the 'whats' (perceptions) under research ${ }^{42}$. Discussion and reflection were encouraged using focus group discussions (FGDs) ${ }^{43}$. Qualitative research can direct researchers to underlying behaviours, attitudes and perceptions that influence health outcomes and can help to explain social and programmatic obstacles to informed choice or the use of services ${ }^{31}$. Because of South Africa's history of enforced racial segregation, and the complex intersection of race with identity, perception, and experience (including potentially access to healthcare services) ${ }^{18}$, the groups were racially delineated into 'black' and 'white' participants. FGDs were also divided according to experience (recent or indirect) of hospital services (public or private). Literature suggests that recent users of both private and public sectors are generally more satisfied with services than those with no direct recent experience ${ }^{\prime \prime}$ 40,41 . Furthermore, users of private hospitals are reported to hold a more negative view of public hospitals, which also highlights the importance of distinguishing between views based on perceptions and those based on actual experience ${ }^{\mid 1,41}$. 'Recent experience' was defined as 'own' admission in the previous year or admission of a friend or relative close to the participant.

\section{Sampling and participants}


Table I: Constitution of focus groups

\begin{tabular}{|c|c|c|}
\hline & Black & White \\
\hline \multirow[t]{2}{*}{ Private hospitals } & Group I: Recent direct experience of private hospital. & Group 3: Recent direct experience of private hospital. \\
\hline & $\begin{array}{l}\text { Group 2: No recent direct experience, but would choose to } \\
\text { go to private hospital should they require health care now. }\end{array}$ & $\begin{array}{l}\text { Group 4: No recent direct experience, but would choose to } \\
\text { go to private hospital should they require health care now. }\end{array}$ \\
\hline \multirow[t]{3}{*}{ Public Hospitals } & Group 5: Recent direct experience of public hospital. & Group 7: Recent direct experience of public hospital. \\
\hline & $\begin{array}{l}\text { Group 6: No recent direct experience, but would choose to } \\
\text { go to public hospital should they require health care now. }\end{array}$ & $\begin{array}{l}\text { Group 8: No recent direct experience, but would choose to } \\
\text { go to public hospital should they require health care now. }\end{array}$ \\
\hline & Black & White \\
\hline \multirow[t]{2}{*}{ Private hospitals } & Group I: Recent direct experience of private hospital. & Group 3: Recent direct experience of private hospital. \\
\hline & $\begin{array}{l}\text { Group 2: No recent direct experience, but would choose to } \\
\text { go to private hospital should they require health care now. }\end{array}$ & $\begin{array}{l}\text { Group 4: No recent direct experience, but would choose to } \\
\text { go to private hospital should they require health care now. }\end{array}$ \\
\hline \multirow[t]{2}{*}{ Public Hospitals } & Group 5: Recent direct experience of public hospital. & Group 7: Recent direct experience of public hospital. \\
\hline & $\begin{array}{l}\text { Group 6: No recent direct experience, but would choose to } \\
\text { go to public hospital should they require health care now. }\end{array}$ & $\begin{array}{l}\text { Group 8: No recent direct experience, but would choose to } \\
\text { go to public hospital should they require health care now. }\end{array}$ \\
\hline
\end{tabular}

A total of eight focus groups were constituted according to race (black and white participants), and previous experience with public and private hospitals, as illustrated in Table I above.

Given the complex configuration of these groups, snowball sampling was used to recruit participants ${ }^{44}$. The first author approached providers (working in private and public hospitals), recent patients, colleagues, family members, and acquaintances, for referrals to potential participants. In turn, potential participants were asked to introduce other candidates who expressed willingness and interest in the study. Interested candidates were supplied with the first author's details and made contact. Recruitment proceeded until each group comprised between four and eight participants, which is considered a good size for focused discussion ${ }^{43,44}$. Of the I 29 people who were approached to take part in the study, a total of 54 participated.

\section{Data Collection}

FGDs were run between March and November 201 I in Johannesburg, at venues and times convenient for participants. Discussions were facilitated in English (with white participants), and Sesotho and English (with black participants). Sessions took between 90 120 minutes and were audio-recorded and immediately translated and transcribed verbatim. Translation was confirmed with trusted Sesotho-speakers to get consensus on the choice of terminology.

A topic guide was used to facilitate discussion around perceptions of public and private hospitals and whether participants would use these services in the future. Key points of discussion included quality of care, cleanliness, patient satisfaction, staff attitudes, the extent to which views were shared within the group, the origins of participants' perceptions, and recommendations for improving the state of public hospitals.

\section{Data Analysis}

Thematic content analysis was employed to explore the themes that emerged inductively from the groups and through the anticipated categories based on the literature and research questions (deductive analysis). Inductive and deductive codes were developed and analysis proceeded until saturation was reached.

Primary coding - grounded in the text by using the words of the respondents - was initially carried out, followed by higher order coding to consolidate these primary codes. Thematic development then followed where the higher order codes were converted into themes and sub-themes ${ }^{31}$. To ensure a process of 'trustworthiness' and reliability ${ }^{31}$ coding was carried out independently by the authors. Codes were then compared and consensus built around the emerging themes. 'Atypical', as well as 'typical', themes were examined ${ }^{3 !}$. Links were drawn and analysed between the different racial groups, direct past experience of private and public sectors, and expressed intention/hope to utilise either service in future.

\section{Ethics}

Ethical clearance was obtained from the University of the Witwatersrand Committee for Research on Human Subjects- Medical. Written informed consent was obtained from each participant; including permission to audio-record the FGDs.

\section{FINDINGS}

Previous studies have shown that white patients are more likely to report excellent service in health care overall than their black African counterparts, and that recent users of both sectors report better satisfaction with services than those with no direct recent experience $^{22,23}$. In this study, differences in perceptions based on race and experience of private or public hospitals did not emerge, although those with recent direct experience of a public hospital held a more positive view of the public sector as compared to those without. For those without recent direct experience of either sector, perceptions were derived from hearsay, word-of -mouth and media reports.

For all groups, regardless of race or experience, three broad themes emerged. The first was an almost-automatic initial perception that private hospitals are "good" and state hospitals "bad". We call this theme "Beauty and the Beast" to convey the positive and negative split in representation between private and public hospitals, explored through sub-themes around hospitality and patient empowerment. The second theme suggests "A more complex picture", which challenges "the thin line between good and bad", particularly in light of costs and quality of care in private and public hospitals. The third theme pertains to "The need to build trust and confidence in public health services" in order to convince "unconvinced users" of the value of public sector care.

\section{Theme I: Beauty and the Beast: the Private- Public Split}

When asked about their perceptions of public and private hospitals, for all groups, there was an immediate splitting of private into 'good' and public into 'bad'. This dichotomy was expressed around subthemes of hospitality, with private facilities emerging as hospitable and caring; and as disempowerment for patients using public hospitals.

\section{Hospitality and the cared-for private patient}

Positive comments regarding private hospitals included respectful, caring staff, their medical expertise and skills, as well as their productive work ethic.

...everybody knows their job, they know what they're supposed to do (G2: Black, no recent experience, would choose private).

By contrast, public hospitals were immediately associated with negative, even abusive staff attitudes, neglect, and feeling unsafe and uncared for: 
...they have poor attitudes, a very poor attitude towards their job, towards you as a patient (G2: Black, no recent experience, would choose private).

Furthermore, poor facility maintenance, shortages of equipment and supplies, and large workloads were raised. These were seen to impact negatively on productivity and quality of care.

'You take what you get and play by their rules'- the disempowered public patient vs the empowered private patient

In discussing their immediate reflections on the public sector, participants spoke of disempowerment, particularly through patient relationships with nurses. Some recent users of public hospitals explained that they had resigned themselves to silently 'putting up' with abuse and ill-treatment without complaining so as to avoid further victimisation, not only from a particular nurse, but from the entire staff, in front of other patients, which would have left them feeling even more powerless and vulnerable.

You just take what you get, you have no choice but to grin and bear it, what can I do [...] We have less power, have to play by their rules, you take what you get. (G5: Black, recent experience public)

By contrast, participants in all the groups felt that patients are more empowered in private hospitals because, as fee-paying customers, they feel they have the right to complain, whereas in public hospitals that right was taken away by virtue of the service being 'free':

I have the power to complain in a private hospital, I don't have to tolerate all the nonsense. (G2: Black, no recent experience, would choose private)

\section{Theme 2: A More Complex Picture: The Thin Line between Good and Bad}

As the discussions progressed in each group, there was a shift away from representing private and public hospitals as 'all good versus all bad' to a more complex understanding of both. Methodologically, this shift highlights the importance of group dynamics, as well as the ways that group discussions may change over the course of time $^{43}$. Through the process of each focus group, participants subtly challenged each other and introduced new ideas to the discussion. Questions were raised about whether private hospitals are 'really as good' as they are perceived to be. Additionally, some participants started expressing empathy towards public hospitals and voicing opinions that sought to justify reasons for the 'poor condition' that they are in. And so the categories in this theme are: "Is the private health sector all that good and the public sector all that bad?" as well as "The lesser of the two evils".

Doubts about the 'goodness' of private hospitals emerged around quality of care and affordability. For example, some participants acknowledged that infections could be acquired in either sector:

She got an infection in a private hospital; [yet] it's more acceptable when it happens in a private hospital which is a dangerous way of looking at things. (G3: White, recent experience private)

Participants also noted that private hospitals are expensive and only accessible to those with medical insurance, while simultaneously lauding public hospitals as affordable.

Even if you would have to pay [in the government hospital], but you would never pay as much as you do in the private. (G2: Black, no recent experience, would choose private)

Over-servicing for profit gains was another negative concern expressed about private hospitals. Even those who would choose to go to a private hospital felt that certain medical procedures might be carried out unnecessarily.

Those tests can be very expensive. And sometimes you get the feeling they don't actually need to do it but they do it anyway because they can. (G4: White, no recent experience, would choose private)

Some participants also felt that there was less overcrowding in the private hospitals and that they are well resourced to provide health care services, whereas government hospitals are expected to deliver the same quality of service with fewer resources:

It's easy to say that the nurses in the private hospitals do their jobs and it's true they do, but they have no reason not to. They have all the equipment they need at their fingertips so they actually have no excuse for not doing their jobs properly. (G4: White, no recent experience, would choose private)

Even within resource constraints, though, some suggested that public hospital personnel are skilled and well-qualified to do their jobs. There was also acknowledgement that expert specialists, as well as good treatment and care, are available in public hospitals along with multi-disciplinary team interventions.

\section{Theme 3: The Unconvinced Service User: The Need to Build Trust and Confidence in the Public Health Sector}

Although a more nuanced shift occurred from a "Beauty and the Beast" split, to a "More Complex Picture" in the course of each focus group discussion, it is noteworthy that none of the participants said that they would willingly choose future public care if they could afford treatment in the private sector instead. While sympathetic to the constraints in the public sector, these remained a barrier to their decisions. This indicates that there may be a difference between sympathising with the public sector context and actually utilising public health services. Public hospital users felt that they had no choice in the matter due to financial constraints, but were similarly suspicious and doubtful about future quality of public sector care.

It's like flying an airline that you know has been crashing a lot of planes, you wouldn't trust them completely ever again. (GI: Black, recent experience public)

Experiences and perceptions influence future health-seeking decisions. Unacceptable care and broken public trust are difficult to restore. However, most of the participants across all eight groups felt that public hospitals would be willingly accessed by more members of the public if improvements were made and there was visible proof of positive change.

I would probably go, but will have to be $100 \%$ sure that they have improved (GI: Black, recent experience public).

When asked to suggest specific ways to improve public hospitals, recommendations included: benchmarking public hospitals against private hospitals, the government making financial investment into public hospitals, improvements in security, buildings and equipment, increased staffing and improvements in staff attitudes, and better communication. These suggestions can be mapped onto many of the initiatives that are currently part of the $\mathrm{NHI}$ as discussed in the next section.

\section{DISCUSSION}

To facilitate South Africa's journey towards universal health coverage UHC, it is important to understand public views and perceptions. NHI will require public funds and the public - people - are intended to benefit through improvements in quality of care, access and equity ${ }^{3}$. A critical task for $\mathrm{NHI}$ reform is to integrate the country's 'two-tier' health system, which remains inequitably divided between private and public sectors. In our study, this split was almost-automatically reproduced through a "Beauty and the Beast" dichotomisation of private and public hospitals. Yet, over the course of conversation, this perception softened, turning to sympathy towards public hospitals and a questioning of whether uncritical veneration of private hospitals is indeed justified. Additionally, recent users of both sectors reported being more satisfied with the care they received than those without recent experience $e^{10,40,41}$. 


\section{Perceptions matter}

QoC is closely linked to acceptability of health services. Acceptability involves the extent to which public perceptions, expectations and experiences of care are 'fitted' to the actual care provided ${ }^{16}$. QoC includes concepts such as discipline, responsiveness and assurance, which contribute to a climate of trust and acceptability between health service providers and users ${ }^{45}$. Discipline describes the sense of order in a given service environment and is reflected in the behaviours of staff and appearance of the overall hospital environment ${ }^{37}$. The extent of discipline influences perceptions of service quality ${ }^{37}$ and a well-disciplined institutional culture may attract patients to particular facilities and providers ${ }^{10}$. In our study, participants perceived the "beauty" of the private sector in positive staff behaviour (respectful treatment of patients, efficient, caring service) as well as a clean physical environment. By contrast, the "beast" of the public sector was largely perceived to lack discipline through disrespectful, 'uncaring' providers and lack of cleanliness.

Addressing issues of discipline, such as improving the clinic facility aesthetics and cleanliness, will be vital for instilling patient confidence and trust ${ }^{37}$. Nationally, the Office of Health Standards Compliance and the establishment of the OHSC, the Facility Inspection Teams (FIT) and the National Core Standards (NCS) for Health Establishments in South Africa, aim to benchmark the quality of care against which service delivery can be monitored ${ }^{7,45}$. Within districts, the Ideal Clinic (introduced in 2015) along with infrastructural improvements, are also important initiatives ${ }^{38,45,46}$. While these measures should go some way to addressing the acceptability issues raised in this study, their impact would need to be monitored and evaluated.

The willingness of staff members to be helpful and to provide prompt service - responsiveness - is an important component of QoC. So too is assurance that providers are capable and able to deliver quality, needed care ${ }^{37}$. Despite concerns about staff discipline and responsiveness, participants did perceive the public sector workforce to be skilled and well qualified. Yet, such assurance is not well communicated and improvements in public sector communication were recommended across the focus groups. Better implementation of person-centred policies such as 'Batho Pele' (People First) and the Patients' Rights Charter, in parallel to NHI reforms, may help to alleviate patient feelings of uncertainty and lack of confidence in public sector hospitals, while simultaneously upholding their right to dignity ${ }^{38}$.

Acceptability of services is just one aspect of accessible care affordability and availability barriers may still prevent people from reaching services, even if in-facility care is acceptable and built on trust $^{16,29}$. Going forward, while improving quality of care, there is a simultaneous need to find ways to address issues such as distances to health facilities and transport costs. Some NHI reforms, for example contracting of general practitioners into clinics, Ward-based Outreach Teams of community health workers, and the provision of maternity waiting homes intend to do this, and could simultaneously enhance acceptability of public services.

\section{Limitations}

In this study, there was no differentiation between the 'types' of public hospitals discussed (district, secondary, tertiary, etc.). Thus further exploration of public hospitals recognising the different levels of care delivered will be important. Furthermore, perceptions of public health services go beyond hospitals and include clinics and outreach services too. Although discussion was focused on hospitals, there is the risk that participants were presenting perceptions of healthcare across all layers of the system.

\section{CONCLUSION}

Ultimately health system reform in any avenue has an impact on all facets of health care services, Occupational Therapy included. It is through acceptability and trust that any health system reform will eventually gain approval and buy-in from the public. Even where public service users are rendered 'choiceless' due to affordability barriers to private services, acceptable public care is a necessary condition for achieving UNC ${ }^{9}$. A person-centred approach to health system strengthening requires that the public (as users and funders) should be at the centre of UHC. That study participants without direct experience of public hospitals were more negative about QoC than those with first-hand experience, suggests the need for a proactive strategy of public engagement, including the profiling of 'good' stories from those who can tell them. Better communication and public involvement in the proposed reforms more generally may also alter negative perceptions. The National Department of Health in South Africa needs to respond proactively to negative media reports and make an effort to highlight examples of good practice. This study showed that there is a positive, sympathetic voice towards the public sector and health policy should be targeted towards further converting the "beast" into the "beauty".

\section{DECLARATION}

No funding was received for this research and there is no possible bias of any of the authors' affiliation to subject matter.

\section{ACKNOWLEDGMENTS}

We acknowledge the support of the South African Research Chairs Initiative programme of the Department of Science and Technology, administered by the NRF (87369). We thank Ermin Erasmus who contributed to the initial conceptualisation and design of the project and express our sincere gratitude to all who took part in the study and generously shared their stories. We are indebted to the two peer reviewers and editors for the insightful, constructive comments that have helped to shape this article.

\section{REFERENCES}

I. Gqirana T. NHI to reduce cost of healthcare. Mail and Guardian. 2015.

2. Global Coalition for Universal Health Coverage. Health for All: Universal Health Coverage Day; 2015.

3. Health NDo. National Health Insurance for South Africa. In: Health NDo, (ed.). Pretoria; 2017.

4. Sheikh K and Gilson L. Science and practice of people-centred helath systems. Health Policy and Planning. 2014; 29.

5. World Health Organization. The World Health Report [2010]: Health Systems Financing; the Path to Universal Coverage; 2010.

6. World Health Organization. Towards people-centred Health Systems: An Innovative Approach for better helath outcomes. In: World Helath Organization Regional Office for Europe doHSaPH, (ed.); 2013.

7. Moleko W, Msibi E and Marshall C. Recent developments in ensuring qualty of care in health establishments in South Africa. In: Padarath $A$ and English R, (eds.). South African Health Review. 2013/14. Durban; 2014.

8. Minister of health. National Health Insurance. Policy Paper. Government Notice 657. Pretoria; $201 \mathrm{I}$.

9. Health Mo. White paper on National Health Insurance. In: Health Do, (ed.). Pretoria; 2015.

10. Mclntyre D, Okorafor $O$, Ataguba J, et al. Health care access and utilisation, the burden of out-of-pocket payments and perceptions of the health system: Findings of a national househols survey; 2009a.

II. Mclntyre D, Thiede M, Nkosi M, et al. Shield Work Package I Report: A Critical Analysis of the current South African Health System; 2007a.

12. Krugg $E$ and Alarcos $C$. Strengthening health systems to provide rehabilitation services. Bulletin of the World Health Organization. 2017; 95

13. Goudge J, Akazili J, Ataguiba J, et al. Social solidarity and willingness to tolerate risk-and income related cross subsidies within health insurance: experiences form Ghana, Tanzania and South Africa. Health Policy and Planning. 2012; 27: i55-i63.

14. Broomberg J. Consultative investigation into low income medical schemes. 2006.

15. World Health Organization. Primary Helath Care (Now more than ever). In: Organization WH, (ed.). World Health Report. Geneva; 2008. 
16. Mclntyre D, Thiede M, Nkosi M, et al. Health care Financing and Expenditure. . In: Harrison S BR, Ntuli A, (ed.). South African Health Review 2007. Durban: Health Systems Trust; 2007b.

17. Coovadia H, Jewkes R, Baron P, Sanders D and D M. The health and health system of South Africa: historical roots of current public helath challenges. The Lancet. 2009; 374: 8I7-34.

18. Ataguba J and Mclntyre D. Paying for and receiving benefits from helath services in South Africa:is the health system equitable? Health Policy and Planning. 2012; 27: i35-i45.

19. Wale K. SA Reconciliation Barometer Survey: 2013 Report. Institute for justice and reconciliation; 2013.

20. Zwi A, Bruhga $R$ and Smith E. Private healthcare in developing countries. BMJ. 200I; 323: 463-4.

21. Day $C$ and Gray A. Health related indicators. In: A N, (ed.). South African Health Review 1998. Durban: Health Sytems Trust, 1998. 3-16.

22. Rispel L, Blaauw D, Chirwa $T$ and de Wet K. Factors influencing agency nursing and moonlighting among nurses in South Africa. Global Helath Action. 20I4; 7.

23. Pillay R. Combined Public Sector Report. National Forum for Occupational Therapy in the public sector; 2017.

24. Gilson L. Trust and the development of health care as a social institution. Social Science \& Medicine. 2003; 56: 1453-68.

25. Gilson $L$ and Erasmus E. Supporting the retention of health resources for health: SADC policy context. In: (HST) RNfEiHiSAEaHST, (ed.). Centre for Health Policy, School of Public Health University of Witwatersrand; 2005a.

26. Gilson L, Palmer $\mathrm{N}$ and Schenider H. Trust and health worker performance: exploring a conceptual framework using South African performance. Social Science \& Medicine. 2005b: 14I8-29.

27. Schneider $H$, Barron $P$ and Fonn $S$. The promise and the practice of transformation in South Africa's helath system. In: State of the nation South Africa. State of the nation South Africa; 2007.

28. Rispel $L$, de Jager $P$ and Fonn $S$. Exploring corruption in the South African helath sector. Health Policy and Planning. 20I5; 0: I-II.

29. Thiede $M$, Akweongo $P$ and Mclntyre $D$. Exploring the dimensions of access. In: Mclntyre D and Mooney G, (eds.). The economics of health equity. Cambridge University Press; 2007: 103-23.

30. Ulin P, Robinson E and Tolley E. Qualitative methods in Public health- A field giude for applied research. United States of America: Jossey-Bass, 2004.

31. Myburgh N, Solanki G, Smith M and Lalloo R. Patient satisfaction with helath care providers in South Africa: the influence of race and socioeconomic status. International journal of Quality Health Care. 2005; 17: 473-7.

32. Holthof $B$. Total quality in acute care hospitals: guidelines for hospital managers. Health Policy. 1991; 18: 243-50.

33. Kalda R, Polluste $K$ and Lember $M$. Patient satisfaction with care is associated with personal choice of physician. Health Policy. 2003; 64: 55-62.

34. National Department of Health. National Core Standards for Health Establishments in South Africa. In: Department of Health, (ed.). Tshwane, South Africa: National Department of Health; 201 I.

35. Sandoval A, Barnsley J, Berta W, Murray M and Brown A. Sustained public preference on hospital performance across Canadian provinces. Health Policy. 2007; 83: 246-56.

36. Lafond K. Improving the quality of investements in health: Lessons on sustainability. Health Policy and Planning. 1995; 10: 63-76.

37. Andaleeb S. Service quality perceptions and patient satisfaction: a study of hospitals in a developing country. Social Science \& Medicine. 200I; 52: 1359-70.

38. Fryatt $R$ and Hunter J. The ideal clinic in South Africa: Planning for implementation. In: Padarat A, King, J and English R, editors. South African Health Review; 2015.

39. Bratton M. Are you being served? Popular sstisfaction with health and education services in Africa. Afro barometer Working Paper no 65; 2007.

40. Gauteng DOH and CIET Africa. Social Audit on Health Service Performance. In: Department of Health, (ed.); 2003.

4I. Kaiser Foundation. Kaiser National Household Survey. In: Foundation K, (ed.); 1998.

42. Gaskell G. Qualitative Researching with text, image and Sound. A practical handbook; 2000.

43. Kitzinger J. Introducing focus groups in qualitative research. In: Mays $\mathrm{N}$ and Pope C, (eds.). Health Care. London: BMT Publishing Group; 1996: 36-45.

44. Pope $C$ and Mays N. Qualitative Research in Health care. England: Oxford University Press; 2006.

45. Gilson L. Acceptability, trust and equity. In: D M and Mooney G, (eds.). The economics of health equity. England: Cambridge University Press; 2007: I 24-47.

46. Ramjee S, Vierya T, Abraham M, Kaplan J and Taylor R. National Health Insurance and South Africa's private sector. In: Padarath A and English R, (eds.). South African Health Review. Durban; 20I3/I4.

47. National Department of Health. Department of Health Strategic Plan 20I5/16 - 2019/20. In: National Department of Health, (ed.). Pretoria, South Africa; 2015.

Corresponding Author

Lebogang Maseko

Email: Lebogang.maseko@wits.ac.za 